\section{ASSOCIATION OF GESTATIONAL DIABETES MELLITUS WITH MATERNAL OBESITY AND PREECLAMPSIA: HOSPITAL-BASED CROSS-SECTIONAL STUDY}

\section{Saira Jahan ${ }^{\bowtie}$, Wardah Ajaz Qazi ${ }^{2}$, Maria Khalid ${ }^{3}$, Urooj Rafi ${ }^{4}$}

\begin{abstract}
OBJECTIVE: To determine the association of gestational diabetes mellitus (GDM) with maternal obesity and Preeclampsia in antenatal patients attending Pakistan Railway General hospital (PRGH) Rawalpindi, Pakistan.

METHODS: This cross-sectional survey was conducted in PRGH Rawalpindi, Pakistan from February-April 20I5. By using convenient sampling technique, 60 pregnant women, aged 18-38 years with gestational age more than 20 weeks were included. Thirty diagnosed GDM women were taken in one group while 30 non-GDM women in other according to the diagnostic criteria of 75-g, 2-h oral glucose tolerance test recommended by American diabetes association. Data was collected in a self-designed structured questionnaire including demographics, routine examination of urine samples while body weights were measured in kilograms and heights in centimeters for determination of obesity according to body mass index (BMI) classification that for normal is (I8.5-24.9), over-weight $(25-29.9)$ and obese $(>30)$.
\end{abstract}

RESULTS: In group of women with GDM, 5 (16.6\%) had normal weight, 16 $(53.3 \%)$ were found to be overweight while $9(30 \%)$ were obese and $0(0 \%)$ were under-weight according to BMI table. In the second group of non-GDM, I 8 women $(60 \%)$ had a normal weight while $6(20 \%)$ were overweight and 6 (20\%) were obese. Hence there were more over-weight patients with gestational diabetes with a significant association $(p<0.05)$. On the other hand, 5 (16.66\%) GDM women and 3(I0\%) non-GDM women had preeclampsia $(\mathrm{p}>0.05)$.

CONCLUSION: A significant association of GDM with maternal obesity was observed in our population whereas preeclampsia with GDM had no significant association.

KEY WORDS: Gestational Diabetes Mellitus (MeSH); GDM Mothers (non$\mathrm{MeSH}$ ); Maternal Obesity (non-MeSH); Preeclampsia $(\mathrm{MeSH})$; Body Mass Index (MeSH).

THIS ARTICLE MAY BE CITED AS: Jahan S, Qazi WA, Khalid M, Rafi U. Association of gestational diabetes mellitus with maternal obesity and preeclampsia: Hospital-based cross-sectional study. Khyber Med Univ J 2018;10(1):19-22.

\section{INTRODUCTION}

$D$ regnancy is a noteworthy acknowledging risk attribute for persistent or new obesity among women.' The incidence of obesity distinctive as a body mass index [BMI] of $30 \mathrm{~kg} / \mathrm{m}^{2}$ is frighteningly high, and possessed $33.8 \%$ amongst US adults in 2008. ${ }^{2}$ According to United State
Statistics, National Longitudinal Survey of Youth; the pregnant females were 3 to 4 times more inclined to have stoutness within 5 years after their labor as compared to ladies without offspring. ${ }^{3}$ For that point, young ladies are prone to get short term and long term obesity related complications, from diabetes mellitus and hypertension in consequent pregnancies ${ }^{4}$ to chronic
四 Biochemistry Department, Islamic International Medical College, Rawalpindi Riphah International University, Islamabad, Pakistan

Email:docsaraiimc@gmail.com Tel: +92-34515182331

2 Foundation University Institute of Rehabilitation Sciences Foundation University, Islamabad, Pakistan

3 Yusra Institute of Rehabilitation Sciences, Islamabad, Pakistan

4 Pakistan Railway Hospital, Rawalpindi, Pakistan

Date Submitted: February 03, 2017

Date Revised: November 26, 2017

Date Accepted: January 07, 2018

cardiovascular ailment with indisputably death. $^{5}$

Increased weight during pregnancy is the tenacious interpreter for obesity during pregnancy. ${ }^{6}$ As an endeavor in part to minimize the tremendously elevated incidence of obesity amongst women in the US, the Institute of Medicine (IOM) amended gestational weight gain rule; in $2009^{8}$; suggested smaller weight gain for women with higher pre-pregnancy body mass indices (BMI). But still less than one-third of pregnant women present with weight gain higher than IOM recommended levels.'

During pregnancy increased maternal weight is linked with various hostile pregnancy consequences, along with higher incidence of cesarean section, complicated vaginal delivery, fetal macrosomia, ${ }^{10}$ and postpartum weight management in the mothers." Furthermore, offspring that lead to weight gain of mother may also be flabby and overweight in later years. ${ }^{12}$

An increase in incidence of women with gestational diabetes mellitus (GDM) that gain weight is observed. ${ }^{13}$ Various meta-analyses and systemic reviews have documented a strong connection amongst obesity and diabetes in pregnancy; in contrast with women having normal weight, fat mothers have more than triple likelihood of developing GDM. Additionally, obese mothers are expected to have higher glucose levels that don't get normal at the end of GDM. ${ }^{14}$ Women with GDM have a higher chances of developing preeclampsia $^{15}$ and fairly half of women 
with a history of GDM develop type 2 diabetes mellitus within 5 to 10 years after delivery. ${ }^{13}$ Children of mothers with GDM are not only prone to develop macrosomia and have higher muscle to fat quotients at birth, but also at greater risk of developing higher blood pressure and type 2 diabetes in later life. ${ }^{14}$ As a result, maternal obesity develops glucose intolerance in pregnancy, which leads to increase in weight and diabetes. ${ }^{16}$

As GDM is rising in our population drastically so we wanted to determine its association with factors like maternal obesity and preeclampsia in antenatal patients attending Pakistan Railway General hospital (PRGH) Rawalpindi, Pakistan.

\section{METHODS}

This cross sectional survey was carried out at Pakistan Railway general hospital Rawalpindi, Pakistan from February 2015 to April 20I5. A total of 60 pregnant women were selected in this study after their 20 weeks of pregnancy aged 18 to 38 years according to the inclusion criteria. The sample size was calculated by using OpenEpi online software for sample size determination in health studies. Pregnant women of 20 weeks gestational age were taken because preeclampsia becomes evident after this time period through protein in the urine. Diagnosed 30 GDM women were selected in one group according to the diagnostic criteria of 75-g, 2-h oral glucose tolerance test (OGTT) recommended by ADA while 30 non GDM women in other group. ${ }^{17}$ Permission was taken from the Ethical Review committee of the institute prior to conducting this study. In addition written informed consent was also taken from all the included patients.
Demographics of patients were documented. Initial assessment of the patients by history and clinical physical examination was performed and listed in the performed data compilation sheet. Data was collected through routine examination $(\mathrm{RE})$ urine samples to assess proteinuria for preeclampsia while body weights were measured in kilograms and heights in centimeters for determination of obesity according to body mass index (BMI) classification that for Normal is (18.5-24.9), over weight (25-29.9) and obese (30-34.9). ${ }^{18}$ Data was analyzed by using Statistical Package for Social Sciences (SPSS) Version 20; frequencies and percentages were taken and chi square test was applied to find association between obesity, preeclampsia and GDM.

\section{RESULTS}

In GDM group, 5 out of 30 women $(16.6 \%)$ were in the normal weight range, $16(53.3 \%)$ found to be overweight while $9(30 \%)$ were obese according to BMI table. No woman was found to be under weight as shown in tablel.

In the second group of non GDM, 18 mothers $(60 \%)$ had a normal weight while 6 (20\%) were overweight and 6 (20\%) were obese. Chi square test was applied to find the association between obesity and GDM. There were more over-weight patients with gestational diabetes $(p<0.05)$ as shown in table l.

On the other hand 5 out of 30 women (I6.66\%) with GDM had preeclampsia while $3(10 \%)$ out of 30 had positive preeclampsia in women without GDM, as shown in table II. This study found no statistical significant association of preeclampsia with GDM ( $p>0.05)$.

\section{DISCUSSION}

Hossain P, et al. gave a perspective on obesity and diabetes in the developing world in 2007 in which he mentioned that India and China would be more prone to diabetic epidemics, and the number of diabetics will increase from 84 million to 228 million. ${ }^{19,20}$

lqbal T, et al. did a prospective cohort study in South Asian women at Agha Khan University Hospital Karachi, Pakistan. By measuring BMI he established that increase in body fat percentage is a risk factor of developing GDM along with decrease in physical activity and imbalanced diet. ${ }^{2 !}$

Meta analysis done by Chu SY, et al. conforms to our study that risk of developing GDM was two times higher in overweight, four times in obese and eight times higher in severely obese women when they compared it with normally weighed gestational women. ${ }^{22}$

Montoro $\mathrm{MN}$, et al. compared the insulin resistance in GDM mothers with and without preeclampsia and found women with preeclampsia were less insulin resistant in their third trimester and even fifteen months post partum but had higher blood pressure as compare to non-preeclamptic GDM women. $^{23}$

In our study, we did not find ant significant association of GDM with preeclampsia. Yogev Y, et al. aimed to find the relation of preeclampsia with GDM through retrospective study on I8I3 GDM patients and diagnosed preeclampsia in $9.6 \%$ of them. They established preeclampsia in obese younger women with high nulliparity ratio and associated it with severity of $\mathrm{GDM}^{24}$ on the other hand we did not assess the severity of GDM and

TABLE I: BODY MASS INDEX IN WOMEN WITH AND WITHOUT GESTATIONAL DIABETES MELLITUS

\begin{tabular}{|l|c|c|c|c|}
\hline & BMI* & $\begin{array}{c}\text { GDM }^{\$} \text { women } \\
\mathbf{n}(\%)\end{array}$ & $\begin{array}{c}\text { Non GDM women } \\
\mathbf{n}(\%)\end{array}$ & p-value $^{\#}$ \\
\hline Normal & $18.5-24.9$ & $5(16.67)$ & $18(60)$ & $<0.05$ \\
\hline Over weight & $25-29.9$ & $16(53.33)$ & $6(20)$ & $<0.05$ \\
\hline Obesity & $30-34.9$ & $9(30)$ & $6(20)$ & $<0.05$ \\
\hline & Total & $30(100)$ & $30(100)$ & \\
\hline
\end{tabular}

*Body Mass Index; ${ }^{\$}$ Gestational Diabetes Mellitus; ${ }^{*}$ Chi-Square Test 
TABLE II: PREECLAMPSIA IN WOMEN WITH AND WITHOUT GESTATIONAL DIABETES MELLITUS

\begin{tabular}{|l|c|c|c|}
\hline Preeclampsia & $\begin{array}{c}\text { GDM }^{\text {\$ women }} \\
\mathrm{n}(\%)\end{array}$ & $\begin{array}{c}\text { Non-GDM women } \\
\mathrm{n}(\%)\end{array}$ & p-value $^{\#}$ \\
\hline Yes & $5(16.67)$ & $3(10)$ & $>0.05$ \\
\hline No & $25(83.33)$ & $27(90)$ & $>0.05$ \\
\hline Total & $30(100)$ & $30(100)$ & \\
\hline
\end{tabular}

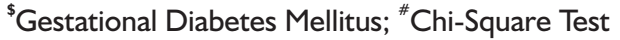

glycemic profile control hence further investigations should be carried out in this regard.

In a study, Wiznitzer A, et al. evaluated lipid profile in pregnant women with GDM and preeclampsia. They found abnormal levels of triglycerides (TGs) in preeclamptics but couldn't relate it to GDM and preeclampsia. ${ }^{25}$

\section{CONCLUSION}

A significant association of GDM with maternal obesity was observed in our population whereas Preeclampsia with GDM had no significant association.

\section{LIMITATIONS \& RECOMMENDATIONS}

Sample size was small and study was conducted in a single hospital setting, so findings cannot be generalized. We have not addressed the lipid profile in gestational women with preeclampsia; research gap should be filled by comparing the lipid profile changes with or without preeclampsia.

Severity of GDM with glycemic profile control should be further investigated with keeping in view the severity level of GDM.

\section{REFERENCES}

I. Herring SJ, Nelson DB, Davey A, Klotz AA, Dibble LV, Oken E, et al. Determinants of excessive gestational weight gain in urban, lowincome women. Womens Health Issues 20I2 Sep;22(5):e439-46. DOI: I0.1016/j.whi.2012.05.004.

2. Flegal KM, Carroll MD, Ogden CL, Curtin LR. Prevalence and trends in obesity among US adults, 1999. 2008 . JAMA $2010 \mathrm{~J}$ a n 20;303(3):235-4I. DOI: I0.100I/jama.2009.2014.
3. Althuizen E, van Poppel MN, Seidell JC, van Mechelen W. Correlates of absolute and excessive weight gain during pregnancy. J Womens Health (Larchmt) 2009 Oct; I8(10):1559. 66. DOI: I0.1089/jwh.2008.1275.

4. American Academy of Pediatrics. Committee on Public Education. American Academy of Pediatrics: Children, adolescents, and television. Pediatrics 200I;I07(2):423-6.

5. Blumberg SJ, Bialostosky K, Hamilton WL, Briefel RR. The effectiveness of a short form of the Household Food Security Scale. Am J Public Health 1999;89(8): I 23 I-4.

6. Gunderson EP, Abrams B, Selvin S. The relative importance of gestational gain and maternal characteristics associated with the risk of becoming overweight after pregnancy. Int J Obes Relat Metab Disord 2000 Dec;24(12):1660-8.

7. Lesko J, Peaceman A. Pregnancy outcomes in women after bariatric surgery compared with obese and morbidly obese controls. Obstet Gynecol 2012 Mar;II9(3):547-54. DOI: I0.1097/AOG.0b0I 3e3 I8239 060e.

8. Chasan-Taber L, Schmidt MD, Pekow P, Sternfeld B, Solomon CG, Markenson G. Predictors of excessive and inadequate gestational weight gain in Hispanic women. Obesity (Silver Spring) 2008 Jul; I 6(7): I 657-66. DOI: 10.1038/oby.2008.256.

9. Chu SY, Callaghan WM, Bish CL, D'Angelo D. Gestational weight gain by body mass index among US women delivering live births, 20042005: fueling future obesity. Am J Obstet Gynecol 2009
Mar;200(3):27I.el-7. DOI: 10.1016/j.ajog.2008.09.879

10. HAPO Study Cooperative Research Group. Hyperglycemia and Adverse Pregnancy Outcome (HAPO) Study associations with neonatal anthropometrics. Diabetes 2009 $\mathrm{Feb} ; 58(2): 453$ - 9 . DOI: |0.2337/db08- I | 2 .

II. Gore SA, Brown DM, West DS. The role of postpartum weight retention in obesity among women: a review of the evidence. Ann Behav Med 2003 Oct;26(2): 149-59.

12. Whitaker RC. Predicting preschooler obesity at birth: the role of maternal obesity in early pregnancy. Pediatrics 2004 Jul; I | 4(I):e29-36.

13. Dabelea D, Snell-Bergeon JK, Hartsfield CL, Bischoff KJ, Hamman RF, McDuffie RS, et al. Increasing prevalence of gestational diabetes mellitus (GDM) over time and by birth Cohort Kaiser Permanente of Colorado GDM Screening Program. Diabetes Care 2005 Mar;28(3):57984.

14. Herring SJ, Oken E. Obesity and diabetes in mothers and their children: can we stop the intergenerational cycle? Curr Diab Rep 20I I Feb; I I ( I ): $20-7$. DOI: I0.1007/s | |892-010-0|56-9.

15. Linne Y. Effects of obesity on women's reproduction and complications during pregnancy. Obes Rev 2004 Aug;5(3): I 37-43.

16. Ehrenberg HM, Mercer BM, Catalano PM. The influence of obesity and diabetes on the prevalence of macrosomia. Am J Obstet Gynecol 2004 Sep;19I(3):964-8.

17.Standards of medical care in diabetes-2013. Diabetes Care 2013 Jan;36(Suppl I):SII-S66. DOI: |0.2337/dc|3-SO | |

18. Akirov A, Shochat T, Masri-Iraqi $\mathrm{H}$, Dicker D, Diker-Cohen T, Shimon I. Body Mass Index and Mortality in Patients with and without Diabetes Mellitus. Diabetes Metab Res Rev 2017 D e c 27. DOI: 10.1002/dmrr.2979 
19. American Association of Diabetes Educators. Addressing obesity via diabetes self-management education and training. Diabetes Educ 2012 Jan-Feb;38(I):I5I-4. DOI: |0.1|77/0|4572|7||433758.

20. Hossain P, Kawar B, El Nahas M. Obesity and diabetes in the developing worlda growing challenge. N Engl J Med 2007 Jan 18;356(3):213-5.

21. Iqbal R, Rafique G, Badruddin S, Qureshi R, Cue R, Gray-Donald K. Increased body fat percentage and physical inactivity are independent predictors of gestational diabetes mellitus in South Asian women. Eur Clin Nutr 2007 Jun;6I (6):736-42.

22. Chu SY, Callaghan WM, Kim SY, Schmid CH, Lau J, England LJ, et al. Maternal obesity and risk of gestational diabetes mellitus. Diabetes Care 2007 Aug;30(8):2070-6.

23. Montoro MN, Kjos SL, Chandler M, Peters RK, Xiang AH, Buchanan TA. Insulin resistance and preeclampsia in gestational diabetes mellitus. Di abetes Care 2005 Aug;28(8):1995-2000.
24. Yogev Y, Xenakis EM, Langer O. The association between preeclampsia and the severity of gestational diabetes: the impact of glycemic control. Am J Obstet Gynecol 2004 Nov; I9I(5): 1655-60.

25. Wiznitzer A, Mayer A, Novack V, Sheiner E, Gilutz H, Malhotra A, et al. Association of lipid levels during gestation with preeclampsia and gestational diabetes mellitus: a population-based study. Am J Obstet Gynecol 2009 Nov;20I(5):482.eI-8. DOI: 10.1016/j.ajog.2009.05.032.

\section{AUTHOR'S CONTRIBUTION}

Following authors have made substantial contributions to the manuscript as under:

SJ: Concept \& study design, acquisition of data, drafting the manuscript, final approval of the version to be published

WAQ: Critical review, drafting the manuscript, final approval of the version to be published

MK: Analysis \& interpretation of data, drafting the manuscript, final approval of the version to be published

UR: Acquisition of data, drafting the manuscript, final approval of the version to be published

Authors agree to be accountable for all aspects of the work in ensuring that questions related to the accuracy or integrity of any part of the work are appropriately investigated and resolved.

\begin{tabular}{|c|}
\hline CONFLICT OF INTEREST \\
Authors declared no conflict of interest \\
GRANT SUPPORT AND FINANCIAL DISCLOSURE \\
NIL
\end{tabular}

This is an Open Access article distributed under the terms of the Creative Commons Attribution-NonCommercial-NoDerivatives 4.0 International License (https://creativecommons.org/licenses/by-nc-nd/4.0/) which permits to reproduce freely in any medium and share the Licensed Material, for NonCommercial purposes only, provided the original work is properly cited. 